DOI: $12737 / 25214$

УДК 658.3.

ЭКОНОМИКА И УПРАВЛЕНИЕ ЗНАНИЯМИ КАК ОПРЕДЕЛЯЮЩАЯ СОСТАВЛЯЮЩАЯ УЛУЧШЕНИЯ ЭКОНОМИЧЕСКОГО СОСТОЯНИЯ РОССИИ

доктор экономических наук, профессор В. Г. Ларионов

ФГБОУ ВО «Московский государственный технический университет им. Н.Э. Баумана», г. Москва, Российская Федерация

В статье рассмотрены различные аспекты кризисной ситуации в России. Указано, что в России наблюдается управленческий, финансовый, экономический кризис, углубляемый агрессивной политикой США и её сателлитов, очевидным становится новый очередной этап геополитического передела мира. Приводятся основные причины, приведшие к сегодняшнему состоянию отечественной экономики. К улучшению создавшегося положения наиболее важным аспектом является инновационная политика Правительства, а также менеджмент знаний, в котором особое место занимают информационные ресурсы и образование трудовых ресурсов. Установлено, что новые идеи, которые разрабатываются высококвалифицированными кадрами, обладающими глубокими знаниями, в современных условиях становятся источником экономического развития региона. Доказана необходимость интеграции образовательных организаций с научными учреждениями на базе производственного комплекса и предпринимательских структур в виде схемы «образование - наука - кадры - инвестиции - фирма - регион - бизнес», представляющей комплекс взаимосвязанных и взаимообуславливающих процессов, которые образуют общий инновационный потенциал любой экономической системы. В Российской экономике, которая основана на знаниях, структура занятых изменяется, всё больший удельный вес приходится на работников интеллектуального труда в структуре работающего населения, увеличивается доля работников с высшим образованием, что представляет собой закономерный результат развития производительных сил в ходе научно-технического прогресса. Одним из современных требований к работнику является его способность к обучению и переквалификации. Особая роль в формировании высокопрофессиональных кадров для Российской экономики отведена информационным ресурсам, ценность значительно увеличивается, они легко тиражируются, обладают повышающейся предельной полезностью, им присущи положительные внешние эффекты и дискриминационные цены.

Ключевые слова: кризис, геополитика, новые технологии, знания, образование, информационные ресурсы, интеллектуальный труд.

\title{
ECONOMICS AND MANAGEMENT OF KNOWLEDGE AS A DEFINING COMPONENT OF IMPROVING THE ECONOMIC CONDITION OF RUSSIA
}

\author{
DSc in Economics, Professor V. G. Larionov
}

Federal State Budget Education Institution of Higher Education «Bauman Moscow State Technical University», Moscow, Russian Federation

\begin{abstract}
The article discusses various aspects of the crisis in Russia. It is specified that in Russia there is management, financial and economic crisis, deepened by aggressive policies of the USA and its satellites, the obvious one is the next stage of new geopolitical repartition of the world. The main reasons that led to the current state of the domestic economy are given. To improve the situation the most important aspect is innovative government policy, and knowledge management, in which special place is occupied by information resources and education of labor resources. It is determined that the new ideas that are being developed by highly qualified personnel, possessing deep knowledge in modern conditions, become a source of economic development of the region. The necessity of integration of educational institutions with research institutions on the basis of industrial complex and business structures in the form of a scheme "education - science - personnel - investment - firm - region - business", representing a set of interrelated and interconnected processes that form the overall innovation potential of any economic system, is proved. In the Russian economy, which is based on knowledge, the structure of employment is changing; an increasing share is
\end{abstract}


for workers of intellectual labor in the structure of the working population, the proportion of employees with higher education increases, which is a natural result of development of productive forces in the course of scientific and technical progress. One of the modern requirements to the employees is their ability to train and re-train. A special role in the formation of highly qualified personnel for the Russian economy is designated to information resources, the value increases significantly, they are easily replicated, have increasing marginal utility, they are characterized by positive externalities and discriminatory prices.

Keywords: crisis, geopolitics, new technologies, knowledge, education, information resources, intellectual work.

\section{Введение}

В России наблюдается денежно-кредитный, финансовый, управленческий кризис, имеющий триединую причину:

- структурный кризис;

- значительное технологическое отставание от развитых зарубежных стран;

- ультралиберальная политика правительства, приводящая к обвальной девальвации рубля, неуправляемой инфляции, снижению уровня жизни большинства населения страны [4].

Сложившаяся ситуация усугубляется агрессивной политикой США и её сателлитов, целью которых является глобальная империалистическая гегемония, поддерживаемая вооруженными силами и военными базами по всему миру, и в первую очередь вокруг России. Поэтому правящие круги США постоянно усиливают политику давления на Россию, создав пояс государств - вассалов, не имеющих собственного мнения и выполняя волю своего хозяина $[5,6,13]$.

В настоящее время становится очевидным новый очередной этап геополитического передела мира. В этой связи Академик РАН С.Ю. Глазьев в своих выступлениях указывает, что эскалация агрессии Соединенных штатов Америки против Российской Федерации и захват ими контроля над Украиной, являющаяся составной частью мировой гибридной войны, которая ведется Вашингтоном в целях удержания в нарастающей конкуренции с Китаем мирового лидерства. При этом в силу сочетания как объективных, так и субъективных обстоятельств, Россия избрана в качестве направления главного удара [3].

Проведение США активной политики «управляемого хаоса» направлено на создание неблагоприятных для России условий развития международных политических, финансовых, экономических процессов, создающих новые угрозы и риски для устойчивого развития России и её регионов $[7,10,16]$. С закрытием для нашей страны доступа к долгосрочным инвестици- ям и новым технологиям, в результате введения против неё США и её сателлитами санкций, Правительству России следует срочно выработать эффективные меры противодействия на основе прагматического перехода на новую инвестиционную модель структурной модернизации экономики страны и её регионов.

\section{Методика исследования}

При анализе генеральной стратегии установления нового миропорядка в позиции различных развитых стран, в частности США, следует исходить из ситуации дальнейшего ускоренного экономического развития этой страны, при обеспечении алчных интересов политиков, военных, банковских магнатов по следующей модели, показанной на рис. 1 [17].

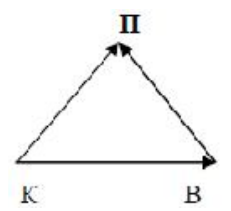

Рис. 1. Связь и взаимная зависимость капитала и военных расходов на прибыль корпораций и государств

где К - инвестируемый капитал в высокоприбыльные глобальные проекты;

В - гибридная война, направленная на свержение неугодных правительств, суверенных, отстаивающих интересы своих стран;

П - прибыль транснациональных корпораций и политиков США.

В этой модели нет места независимым государствам и в первую очередь России.

В своем выступлении на заседании «Меркури Клуб» в апреле 2015 г. ныне покойный академик РАН Е.М. Примаков определил политику руководства государств, начиная с 90-х годов до настоящего времени, в первую очередь развал СССР, шоковую терапию, некомпетентность и чрезмерно раздугый штат государственных чиновников, прозрачность границ, недофинансирование системы здравоохранения, образова- 


\section{Менеджмент. Экономика. Организация}

ния, обороны. Только в последние 2 года резко увеличилось финансирование оборонных отраслей, что сразу сказалось на эффективности деятельности оборонного комплекса. В исправлении и улучшении сложившейся ситуации в экономике нашей страны первостепенную роль играет инновационная политика правительства и менеджмент знаний $[9,11]$.

Инновационное развитие - это цепь реализуемых новшеств, создание предпосылок и условий, которые необходимы для его «воплощения в жизнь», представляющие в совокупности инновационнокреативный потенциал организации, региона, страны. Научные организации выступают в качестве основных участников процесса при переходе на инновационный пугь развития, создающие необходимые материальнотехнические и кадровые предпосылки для выхода на более высокий уровень социально- экономического прогресса страны при тесном взаимодействии с образовательными учреждениями [18].

Вышеперечисленные аспекты можно представить в виде схемы «образование - наука - кадры - инвестиции - фирма, регион - бизнес», представляющей комплекс взаимосвязанных и взаимообуславливающих процессов, которые образуют общий инновационный потенциал любой экономической системы $[1,14]$.

Новые идеи, которые разрабатываются высококвалифицированными кадрами, обладающими глубокими знаниями, в современных условиях становятся источником экономического развития региона. Таким образом, осуществляется инновационно-креативный подход, основанный на инновациях. На рис. 2 представлена структура инновационно-креативного потен- циала организации [8].

Владение информацией определяет темп любого улучшения и развития экономики развитой страны или региона. Информационная компонента является базой любого производства или бизнеса [2]. Фактором притяжения и развития деловой активности становится развитость информационной инфраструктуры (одновременно выступающей инфраструктурой бизнеса), основывающаяся на развитости информационной компоненты, которая одновременно является фактором, индикатором и результатом развития региона и страны в целом.

Компьютерные технологии, компьютерный дизайн, средства связи, ЭВМ, оказали такое же влияние на социально - экономическое развитие всего общества как железные дороги в XIX в. Ресурсом развития выступает информация, в то время как темп данного развития является зрелостью информационных технологий [1].

Главной особенностью экономики, которая основана на знаниях, является то, что данная экономика применяет информационные ресурсы, которым присущи специфические черты, отличающие их от традиционных (табл. 1) [4].

Материальные потоки характеризуют традиционные ресурсы, а нематериальные потоки и запасы информационные. Если знания передаются, тиражируются и используются, то их ценность увеличивается, и наоборот, если знания не используются, то их ценность уменьшается, иногда до нуля. В зависимости от полноты использования знания, их ценность возрастает (т.е. насколько полно они используются производите-

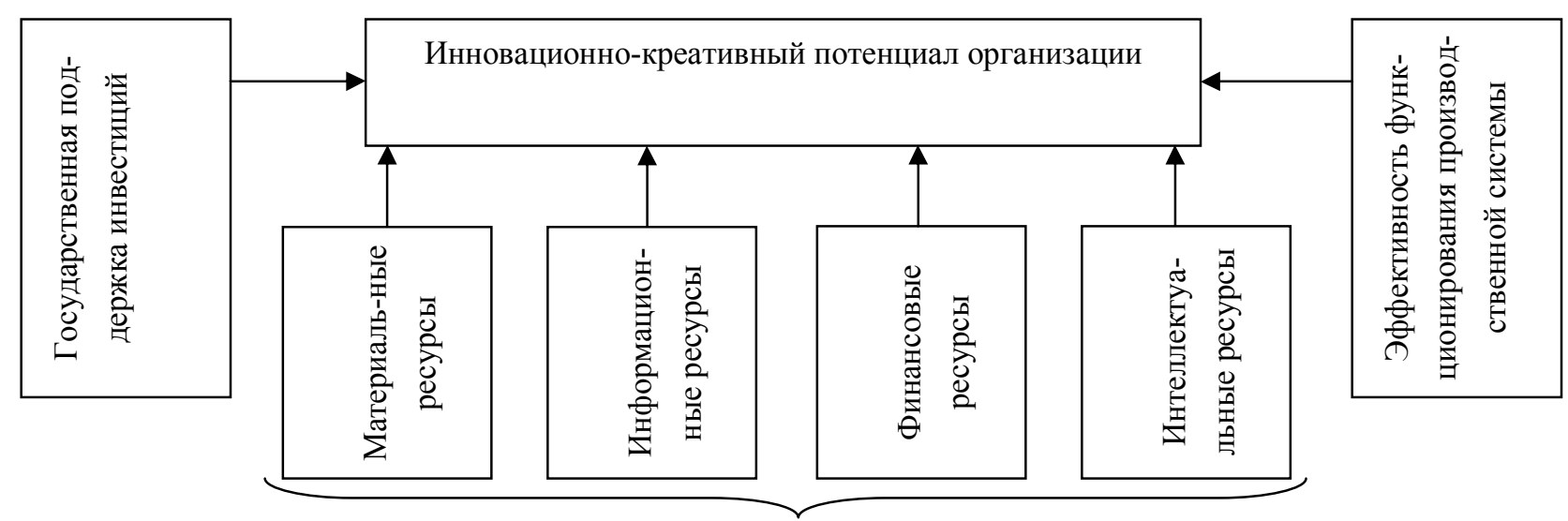

Ресурсная составляющая потенциала

Рис. 2. Структура инновационно-креативного потенциала организации 
Свойства традиционных и информационных ресурсов

\begin{tabular}{|l|l|}
\hline \multicolumn{2}{|c|}{ Традиционные } \\
\hline \multicolumn{2}{|c|}{ Свойства ресурсов } \\
\hline Материальные потоки и запасы & Нематериальные потоки и запасы \\
\hline В процессе использования уменьшаются & В процессе использования увеличиваются \\
\hline Частное благо & Общественное благо \\
\hline Ограниченные & Неограниченные \\
\hline Тиражируемые с большими затратами & Тиражируемые с малыми затратами \\
\hline Убывающая предельная ценность & Сетевые эффекты и возрастающая предельная ценность \\
\hline
\end{tabular}

лем, потребителем и обществом). Это является главным их отличием от основных фондов, которые чем больше используются, тем в большей степени изнашиваются и уменьшают свою стоимость.

Результатыл исследований

Материалы исследований позволили определить возрастающую значимость информационных ресурсов и формирование высококвалифицированных трудовых ресурсов.

Обычные традиционные ресурсы выступают в качестве частного блага, потребляемого одним потребителем и исключая потребление другим. Информационные же ресурсы являются общественным благом, его потребление одним потребителем не исключает потребления другим. Другими словами, информация и знания неотчуждаемы. Все большее количество общественных благ задействуется в процессе современного производства, увеличивающего использование информации и знаний. Данный аспект способствует новому переосмыслению представления экономической теории и классических методов управления.

Доминирование знаний, переход от производства информации и знаний к производству новых технологий обработки информации стало существенной особенностью конца XX - начала XXI в. Применение данных технологий во всех сферах экономики меняет не только сугь процесса производства, но и повышает его конечную эффективность.

В настоящее время в экономике знаний особое место занимают трудовые ресурсы, их образование, должность, квалификация и т.д.

Как правило, в экономике, которая основана на знаниях, структура занятых изменяется. Всё больший удельный вес приходится на работников интеллектуального труда в структуре работающего населения.
Одним из современных требований к работнику является его способность к обучению и переквалификации. Как показывают исследования, работник, получивший более высокий уровень базового образования, отличается большими творческими возможностями и более восприимчив к получению новых знаний. Во многих развитых странах возрастает среднее время, отводящееся людьми на образование, вместе с этим, работодатели все чаще беруг затраты на специальное образование на себя.

Как показывает практика, удельный вес занятых, работающих в творческом ключе, возрастает в развитых экономиках многих стран. Каждый шестой из числа работающих в США работает не по найму (т.е. имеет свой бизнес). Из четырёх новых рабочих мест одно занимает руководитель фирмы или работающий не по найму. За десятилетний период данный показатель увеличился вдвое и продолжает расти. Следует отметить, что за последние 10 лет уровень занятости снизился в тысяче крупнейших компаний США.

Основанная на знаниях экономика - это не только новая структура производства, но и новая структура занятых, а также новое качество занятости. Знатоки своего дела (менеджеры, профессионалы высококвалифицированных услуг) приходят на место безликой рабочей силы. Существенная роль в экономическом развитии принадлежит увеличивающемуся удельному весу профессиональной занятости. Как сулят прогнозы, количество занятых специалистовтехников и специалистов-технологов, а также занятость в управлении организациями и в сфере услуг бизнесу, будет расти опережающими темпами [1].

Необходимо определить границы и внугреннюю структуру фирмы в основанной на знаниях экономике. В последние годы в ЦЭМИ и РАН, прежде 


\section{Менеджмент. Экономика. Организация}

всего в работах В.Л. Макарова и Г.Б. Клейнера разработана системно-интеграционная теория фирмы, согласно которой фирма рассматривается как совокупность семи подсистем, таких как: ментальная, когнитивная, институциональная, культурная, имитационная, технологическая и историческая. Разработанная теория способствует существенному расширению традиционных представлений о продукции фирмы, которая включает в себя не только товары и услуги, но и знания, поведенческие решения и образцы, институты, корпоративную культуру и менталитет и т.д. В связи с чем, представлено об обмене претерпело изменение. Фирмы обмениваются не только товарами и услугами, но и кейсами, институтами и пр.

Важная роль в традиционной экономике принадлежала материальной подсистеме, в то время как в экономике знаний - когнитивной, ментальной, имитационной и иным подсистемам. В условиях современной действительности фокус управления смещается: с материальных потоков и запасов - к нематериальным (т.е. к управлению информацией, культурой фирмы, ментальными моделями сотрудников, созданием прецедентов, институгов, в том числе доверия, корпоративного духа и обмена знаниями).

Аналогично изменяется видение вопроса об инвестиционных процессах. В случае, если говорится об вложениях в интеллектуальный капитал, то наряду с инвестициями средств в элементы интеллектуального капитала (обучение персонала, развитие системы дистрибуции, информационные системы, бренд и т.д.) рассматриваются источники вложения нематериальной природы, такие как: интеллектуальные инвесторы, которые изменяют ментальные модели сотрудников; культурные доноры, которые оказывают влияние на корпоративную культуру; институциональные инвесторы, которые влияют на изменение институгов внугри фирмы; когнитивные инвесторы, которые вкладывают непосредственно свои знания; имитационные доноры, т.е. аналогичные фирмы, которые генерируют свой опыт, который возможно перенести на другую почву.

Развернугая система образования, которая охватывает все большую долю населения, характеризует основанную на знаниях экономику. Для того чтобы обеспечить рост высоко-квалифицированных специалистов, необходимо создавать благоприятные условия для непрерывного образования граждан, развивать их способности к адаптации в условиях меняющихся требований, содействовать международному признанию квалификаций и степеней, которые присуждаются образовательными учреждениями в отдельных странах.

Неуклонно растуг затраты на обучение. Время, расходуемое на подготовку и переподготовку, а также повышение квалификации работников увеличивается, в связи с чем требуется использование новых технологий обучения (таких, как дистанционное образование).

В основанном на знаниях обществе наблюдается такой процесс как нивелирование прежних социальных различий, связанный с тем фактом, что знания неотделимы от человека в отличие от материальных ценностей. Наряду с этим происходит нарождение нового вида социального расслоения, которое основано на интеллектуальных отличиях, а не на классовых. В связи с этим, обеспечение равного доступа к качественному образованию является социальной проблемой.

В последние годы увеличилась доля работников с высшим образованием в странах ОЭСР (организации экономического сотрудничества и развития). Так, например, в период 1975-2000 гг. доля взрослого населения с высшим образованием увеличилась на 19 \% (с 22 $\%$ до $41 \%$ ), в 2014 г. она составила $50 \%$. Однако, такое увеличение является недостаточным при растущем спросе на квалифицированных специалистов.

\section{Заключение}

Подводя итог, основанная на знаниях экономика представляет собой закономерный результат развития производительных сил в ходе научнотехнического прогресса, который обусловливает рост роли знаний и информации в создании благ. Основными признаками экономики, основанной на знаниях, являются:

- одним из факторов производства становится знание;

- ключевым ресурсом выступает информация, а в основу технологического уклада входят электронные информационные технологии;

- основу богатства формируют творческие и интеллектуальные способности человека как для организаций и стран в целом, так и для индивидуумов;

- все больше и больше увеличивается процент работников, занятых интеллектуальным трудом;

- увеличивается количество занятых в третичном 
секторе, в то время как, относительное количество занятых в первичном и вторичном секторах уменьшается;

- вся деятельность реорганизуется в рамках организаций на основе постоянного обмена знаниями между работниками.

Изменение структуры общественного производства способствует экономическому развитию многих стран. Так называемая демассификация производства происходит из-за индивидуализации потребления и снижения тиражности производства. Информационные ресурсы становятся основными факторами производства, наблюдается углубление интеллектуализации.
В результате можно сделать вывод, что в формировании высокопрофессиональных кадров для Российской экономики особая роль отведена информационным ресурсам, ценность которых значительно увеличивается, они легко тиражируются, обладают повышающейся предельной полезностью, им присущи положительные внешние эффекты и дискриминационные цены.

Этому аспекту надо уделять повышенное внимание по всей цепочке интегрированной структуры «образование - наука - кадры - инвестиции - бизнес регион».

\section{Библиографический список}

1. Bezrukova T.L. Modelling and forecasting of innovative development of entrepreneurial structures under the global competition / [Text] / T.L. Bezrukova, A.T.,Gyiazov, A.M.Bazieva // Actual problems of economiics, 2016. - №8 (182). - pp. 344-351.

2. Безрукова, Т.Л. Государственные механизмы обеспечения качества образования [Текст] / Т.Л. Безрукова, В.И. Дмитриев, Е.А. Яковлева // Актуальные направления научных исследований XXI века: теория и практика: сборник научных трудов по материалам международной заочной научно-практической конференции. - Воронеж, 2014. - № 2, Ч. 3 (7-3). - С. 262-265.

3. Безрукова, Т.Л. Взаимоотношение бизнеса и высшего образования в независимом государстве [Текст] / Т.Л. Безрукова, А.Т. Гыязов // Актуальные направления научных исследований XXI века: теория и практика: сборник научных трудов по материалам международной заочной научно-практической конференции. - Воронеж, 2014. - № 2, - Ч. 3 (7-3). - C. 257-262.

4. Bosua, R. Aligning strategies and processes in knowledge management: a framework [Text] / R. Bosua, K. Venkitachalam // Journal of Knowledge Management, 2013. - no.17(3). - pp. 331-346.

5. Беспалов, П.В. Интеллектуальный капитал - стратегический потенциал организации [Текст]: учеб. пособие / П.В. Беспалов, А.Л. Гапоненко, В.И. Корниенко и др.; Под ред. Гапоненко А.Л., Орловой Т.М.; Моск. междунар. высш. шк. бизнеса «МИРБИС» (ин-т). - М.: Соц. отношения, 2003. - 177 с.

6. Гайсельхарт, Х. Обучающееся предприятие в XXI веке [Текст]: учеб. пособие / Х. Гайсельхарт; пер. с нем. Н.В.Маловой. - Калуга: Духовное познание, 2004. - 264 с.

7. Dul, J. Knowledge workers' creativity and the role of the physical work environment [Text] / J. Dul, C. Ceylan, F. Jaspers // Human Resource Management, 2011. - no. 50(6). - pp. 715-734.

8. Fernando de Melo. Quantitative Analysis in Economics Based on Wavelet Transform: a new approach [Text] / Fernando de Melo, V.V. Maslennikov, E.V. Popova, T.L. Bezrukova, I.V. Kyksova // Asian Social Science Vol., 2015. - 11, - no. 20. - pp. 66-74.

9. Funmilola Olubunmi Omotayo Knowledge Management as an important tool in Organisational Management: A Review of Literature [Text] / Funmilola Olubunmi Omotayo // Library Philosophy and Practice, Libraries at University of Nebraska-Lincoln, 2015. - pp. 1 - 23.

10. Ларионов, В. Г. Контроллинг систем управления персоналом [Текст] / В.Г. Ларионов, С.Г. Фалько // Вестник Академии. - 2013. - №4. - С.73-78.

11. Ленская, С. А. Интеллектуальный капитал - фактор экономического развития современной России [Текст]: монография / С.А. Ленская, М.А. Эскиндаров, В.В. Мосин, Г.М. Епихина. - М.: Высшая школа, 2002. - 92 с.

12. Любимова М. А. Анализ моделей обучаемого и обучения и особенности их реализации [Текст] / М. А. Любимова // Лесотехнический журнал - 2016. - №1 - С. 283-289. 
13. Мильнер, Б.3. Управление знаниями в корпорациях [Текст]: учеб. пособие / Б.З. Мильнер, З.П. Румянцева, В.Г.Смирнова, А.В. Блинникова. - М.: Дело, 2006. -304 с.

14. Olkiewicz, Marcin Knowledge management as a determinant of innovation in enterprises [Text] / Marcin Olkiewicz // Management and Innovation For Competitive Advantage, 2015. - pp. 399-409.

15. Основы наукоёмкой экономики (знания - креативность - инновации) [Текст]: учеб. / Под ред. д.э.н., проф. И.А. Максимцева. -М.: Креативная экономика, 2011. - 456 с.

16. Popkova, E.G. Clustering of internet companies as a new course of development of Russia in modern conditions [Text] / E.G. Popkova, I.M. Kuzlaeva, T.L. Bezrukova // Mediterranean Journal of Social Sciences, 2015. - Vol 6, No 4. - pp. 209-218.

17. Стюарт, Томас А. Интеллектуальный капитал. Новый источник богатства организаций [Текст]: учеб. пособие / Т.А. Стюарт. - М.: Поколение, 2007. - 368 с.

18. Sahlberg, P. Teaching and globalization [Text] / P. Sahlberg // International Research Journal of Managing Global Transitions, 2004. - No. 2(1). - pp. 65-83.

\section{Reference}

1. Bezrukova T.L., Gyyazov A.T., Bazieva A.M. Modelling and forecasting of innovative development of entrepreneurial structures under the global competition. Actual problems of economiics, 2016, no. 8(182), pp. 344-351.

2. Bezrukova T.L., Dmitriyev V. I., Yakovleva E.A. Gosudarstvennye mehanizmy obespechenija kachestva obrazovanija [State mechanisms of ensuring quality of education] Aktual'nye napravlenija nauchnyh issledovanij 21 veka: teorija i praktika: sbornik nauchnyh trudov po materialam mezhdunarodnoj zaochnoj nauchno-prakticheskoj konferencii [Actual directions of scientific researches of the 21 century: theory and practice: the collection of scientific works on materials of the international correspondence scientific and practical conference]. Voronezh, 2014, no. 2, Issue. 3 (7-3), pp. 262-265. (in Russian).

3. Bezrukova T.L., Gyyazov A.T. Vzaimootnoshenie biznesa i vysshego obrazovanija v nezavisimom gosudarstve [Vzaimootnosheniye of business and the higher education in the independent state Aktual'nye napravlenija nauchnyh issledovanij 21 veka: teorija i praktika: sbornik nauchnyh trudov po materialam mezhdunarodnoj zaochnoj nauchno-prakticheskoj konferencii [Actual directions of scientific researches of the 21 century: theory and practice: the collection of scientific works on materials of the international correspondence scientific and practical conference]. Voronezh, 2014, no. 2, Issue. 3 (7-3), pp. 257-262. (in Russian).

4. Bosua R., Venkitachalam K. Aligning strategies and processes in knowledge management: framework [Text]/R. Bosua. Journal of Knowledge Management, 2013, no. 17(3), pp. 331-346.

5. Bespalov P. V., Gaponenko A. L., Korniyenko V. I., etc. Intellektual'nyj kapital - strategicheskij potencial organizacii [The intellectual capital - the strategic capacity of the organization]. Moscow, 2003, $177 \mathrm{p}$. (in Russian).

6. Gayselkhart X. Obuchajushheesja predprijatie v 21 veke [The trained enterprise in the 21 century] Kaluga, 2004, 264 p. (in Russian).

7. Dul J., Ceylan C., Jaspers F. Knowledge workers' creativity and the role of the physical work environment Human Resource Management, 2011, no. 50(6), pp. 715-734.

8. Fernando de Melo., Maslennikov V.V., Popova E.V., Bezrukova T.L., Kyksova I.V. Quantitative Analysis in Economics Based on Wavelet Transform: a new approach. Asian Social Science Vol., 2015, 11, no. 20, pp. 66-74.

9. Funmilola, Olubunmi Omotayo Knowledge Management as an important tool in Organisational Management: A Review of Literature Library Philosophy and Practice, Libraries at University of Nebraska-Lincoln, 2015, pp. 1-23.

10. Larionov V. G., Falko S.G. Kontrolling sistem upravlenija personalom [Controlling of personnel management systems] Vestnik Akademii [Bulletin of Academy]. 2013, no. 4, pp. 73-78. (in Russian).

11. Lenskaya S. A., Eskindarov M. A., Mosin V. V., Epikhina G. M. Intellektual'nyj kapital-faktor jekonomicheskogo razvitija sovremennoj Rossii [the Intellectual capital - a factor of economic development of modern Russia]. Moscow, 2002, 92 p. (in Russian).

12. Lyubimova M. A. Analiz modelej obuchaemogo i obuchenija i osobennosti ih realizacii [The analysis of models of the trainee and training and feature of their implementation] Lesotehnicheskii zhurnal, 2016, no. 1, pp. 283-289. (in Russian).

13. Milner B. Z., Rumyantseva Z.P., Smirnova V. G., Blinnikova A.V. Upravlenie znanijami v korporacijah [Management of knowledge in corporations]. Moscow, 2006, 304 p. (in Russian). 
14. Olkiewicz Marcin Knowledge management as a determinant of innovation in enterprises Management and Innovation For Competitive Advantage, 2015, pp. 399-409.

15. Osnovy naukojomkoj jekonomiki (znanija - kreativnost' - innovacii) [Fundamentals of the knowledge-intensive economy (knowledge - creativity - innovations)] Under the editorship of Dr. Econ. Sci., prof. I.A. Maksimtseva. Moscow, 2011. 456 p. (in Russian).

16. Popkova E.G., Kuzlaeva I.M., Bezrukova T.L. Clustering of internet companies as a new course of development of Russia in modern conditions Mediterranean Journal of Social Sciences, 2015, Vol 6, no 4, pp. 209-218.

17. Stewart Thomas A. Intellektual'nyj kapital. Novyj istochnik bogatstva organizacij [Intellectual capital. New source of richness of the organizations] Moscow, 2007, 368 p. (in Russian).

18. Sahlberg P. Teaching and globalization International Research Journal of Managing Global Transitions, 2004 , no. 2(1), pp. 65-83.

\section{Сведения об авторе}

Ларионов Валерий Глебович - профессор кафедры «Экономики и организации производства» ФГБОУ ВО «Московский государственный технический университет им. Н.Э.Баумана», доктор экономических наук, профессор, г. Москва, Российская Федерация; e-mail: vallarionov@yandex.ru

\section{Information about author}

Larionov Valeriy Glebovich - Professor of Department "Economics and production organization" Federal State Budget Education Institution of Higher Education «Bauman Moscow State Technical University», DSc in Economic, Professor, Moscow, Russian Federation; e-mail: vallarionov@yandex.ru

DOI: $12737 / 25215$

УДК 658.512 .88

МЕХАНИЗМЫ И ПРИНЦИПЫ ФУНКЦИОНИРОВАНИЯ СИСТЕМЫ УПРАВЛЕНИЯ ЛЕСОПРОМЫШЛЕННЫМ ПРЕДПРИЯТИЕМ

кандидат экономических наук, доцент С. О. Медведев ${ }^{1}$ кандидат технических наук, доцент А. П. Мохирев ${ }^{1}$

\section{А. А. Керющенко ${ }^{1}$}

О. К. Пузырева ${ }^{1}$

1 - Лесосибирский филиал ФГБОУ ВО «Сибирский государственный аэрокосмический университет имени академика М.Ф. Решетнева», г. Лесосибирск, Российская Федерация

Для того, чтобы повысить эффективность предприятия следует организовать систему управления, которая зависит от четкой структуры предприятия и деятельности всех ее элементов в направлении выбранной цели. Структура управления состоит из всех целей, которые распределяются между различными звеньями, между которыми существуют связи, обеспечивающие координацию отдельных действий по их выполнению. Связь структуры и ключевых понятий управления - его целями, функциями, процессом, механизмом функционирования, людьми и их полномочиями говорит о том, что она оказывает огромное влияние на все стороны работы организации. Организации создают структуру для того, чтобы обеспечивать координацию и контроль деятельности своих подразделений и работников. Структуры организаций отличаются друг от друга степенью разделения деятельности на различные функции - сложностью, степенью использования заранее установленных правил и процедур - формализацией, уровнями, на которых принимаются управленческие решения - соотношением централизации и децентрализации. Для повышения эффективности предприятия в условиях возрастающей конкуренции, руководство должно быстро реагировать на постоянные изменения во внешней инфраструктуре. Это особенно важно для предприятий лесопромышленной отрасли, так как их эффек- 